\title{
Infant feeding, wheezing, and allergy: a prospective study
}

\author{
Michael L Burr, Elizabeth S Limb, Michael J Maguire, Linda Amarah, Beverley A Eldridge, \\ Jane C M Layzell, Terry G Merrett
}

\begin{abstract}
The determinants of wheezing and allergy were investigated in 453 children with a family history of allergic disease. A randomised controlled trial examined the effects of withholding cows' milk protein during the first three months of life and replacing cows' milk with soya milk. The children were followed up to the age of 7 years. Withholding cows' milk did not reduce the incidence of allergy or wheezing. Children who had ever been breast fed had a lower incidence of wheeze than those who had not ( $59 \%$ and $74 \%$ respectively). The effect persisted to age 7 years in the nonatopics only, the risk of wheeze being halved in the breast fed children after allowing for employment status, sex, passive smoking, and overcrowding. Allergic disease was not associated with exposure to tobacco smoke, house dust mite antigen, or cats. Breast feeding may confer long term protection against respiratory infection.
\end{abstract}

(Arch Dis Child 1993; 68: 724-728)

Wheezing is a common symptom in childhood. Its causes include infection, allergy, and exposure to atmospheric irritants such as tobacco smoke. In 1982 a study was set up to investigate prospectively the onset of wheezing in a cohort of children from birth. ${ }^{2}$ The children were selected so as to have a high risk of wheezing illness in two respects: they lived in an area (two valleys in South Wales) known to have a high prevalence of chest disease, ${ }^{3}$ and they all had a parent or sibling with a history of atopic disease.

One objective of the study was to examine the possibility ${ }^{4}$ that withholding cows' milk protein for young infants at high risk of allergy reduces their incidence of asthma. To this end, a randomised controlled trial was conducted in which half the babies were given soya milk instead of cows' milk preparations; no evidence of benefit emerged during the first year of life.'

A further objective of the study was to observe the relationship between various other factors and the development of respiratory symptoms during childhood. Breast feeding was found to be associated with a reduced incidence of wheeze during the first year of life, and this reduction was not attributable to social class, parental smoking habit, or number of siblings, although these factors all had some independent prognostic effects. These and other results from the first year have already been published. ${ }^{125}$ The children have now been followed up to the age of 7 years, and this paper presents the findings at that time.

\section{Methods}

Women attending antenatal clinics were asked whether they, their husbands, or their children had ever had asthma, eczema, or hay fever and those who replied affirmatively were invited to take part in this study. The women were randomly allocated to an intervention group, which was supplied with soya milk as an alternative to cows' milk formulation when the baby was born, and a control group, which was not. Mothers in the intervention group were asked to avoid giving the baby any food containing cows' milk protein for four months, and advised to restrict their daily milk intake to half a pint (284 $\mathrm{ml}$ ) during the pregnancy and while they were breast feeding. Information was collected about the feeding of the infants (including the duration of breast feeding) and other potentially relevant factors. ${ }^{12}$ Samples of dust were taken from the infants' beds, their mothers' beds, and the carpets on which they were most often placed, and examined for mite antigen by means of an inhibitory radioimmunoassay'; the sample with the highest antigen concentration for each child was taken to represent mite exposure. The infants were examined three times during their first year of life by a doctor who was unaware of how the children had been fed. A sample of blood was taken when they were three months old and assayed for milk specific $\mathrm{IgG}_{4}$ antibodies.

At the time of their second to their sixth birthdays the children were sent birthday cards; these cards incorporated a few questions (including an inquiry about wheeze coming from the chest during the past year), which the mothers were asked to answer and return. Each occurrence of the word 'wheeze' on a questionnaire was accompanied by the definition 'Wheeze means a whistling sound, whether high or low pitched, and however faint ${ }^{\prime}{ }^{6}$ About the time of the seventh birthday each child was again invited to a clinic. A detailed questionnaire was administered, and skin tests were performed using standard Bencard antigens for Dermatophagoides pteronyssinus, grass pollen, cat, egg, milk, mixed moulds, and control solution. The children were examined and their mothers interviewed by a 
Table 1 Frequency (\%) of symptoms in boys and girls

\begin{tabular}{|c|c|c|c|c|c|}
\hline \multirow[b]{2}{*}{ Wheeze at any time } & \multirow{2}{*}{$\begin{array}{l}\text { All } \\
(n=453)\end{array}$} & \multicolumn{2}{|c|}{$\begin{array}{l}\text { Bows } \\
(n=243)\end{array}$} & \multirow{2}{*}{$\begin{array}{l}\begin{array}{l}\text { Girls } \\
(n=210\end{array} \\
61\end{array}$} & \multirow{2}{*}{$\begin{array}{l}\text { "o Difference, } \\
\text { bon's-girls } 95 \% \text { "CI } \\
13(+ \text { to } 21)\end{array}$} \\
\hline & & 73 & $\star \star$ & & \\
\hline Asthma (parents' report) & 21 & 26 & $\star$ & 17 & 9 (1) 16 ) \\
\hline Asthma (diagnosis) & 32 & 37 & $\star$ & 25 & $13+$ to 21 \\
\hline Eczema diagnosis) & 36 & 31 & $\star$ & 42 & $-12-20$ to -3 \\
\hline Allergic rhinitis diagnosis) & 26 & 30 & & 22 & $7-1$ to 16 \\
\hline
\end{tabular}

$\mathrm{CI}=$ confidence interval.

Boys 2 girls: ${ }^{\star} \mathrm{p}<0.05 ;{ }^{\star \star} \mathrm{p}<0.01$

consultant paediatrician who did not know their feeding history nor other details of their early exposure to allergens. Peak expiratory flow rate (PEFR) was measured five times, and a simple exercise challenge test was then performed: the children were asked to run for six minutes, and PEFR was measured again after five minutes' rest. The mean of the highest three readings was taken as the true value on each occasion. No attempt was made to standardise speed of running, temperature, or humidity, the exercise being always conducted indoors at ordinary room temperature. Further samples of dust were obtained from the children's mattresses and assayed for Der $p$ I by an enzyme linked immunoadsorbent assay (ELISA) method, giving a between assay coefficient of variation of $14-16 \%$ at the extreme ends of the standard calibration curve.

Ethical approval was obtained for both stages of the study.

\section{Results}

The original cohort comprised 497 babies ( 262 boys, 235 girls). At the age of 7 years, 440 were clinically examined, and detailed questionnaires completed on another 13 children who were living outside the original area, so that information was obtained on $91 \cdot 1 \%$ of the whole cohort.

Table 1 shows the prevalence of a history of symptoms, as reported in various ways. 'Wheeze at any time' refers to the annual questionnaires, including those administered when the child was 1 and 7 years old. 'Asthma (parents' report)' refers to the questionnaire administered when the children were 7 years old, inquiring whether they had ever had asthma. 'Asthma (diagnosis)'

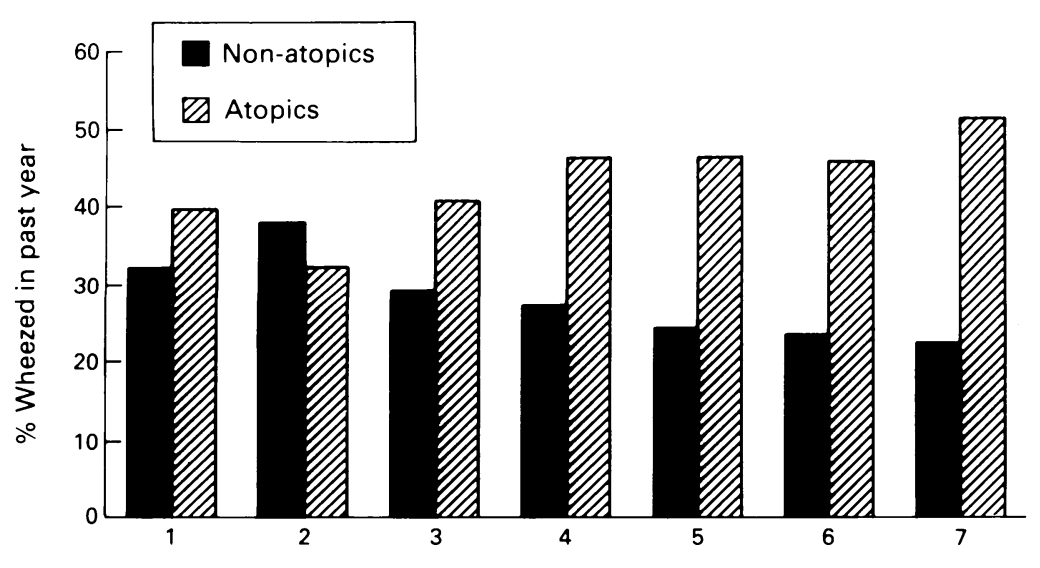

Age (years)

Figure 1 Incidence of wheeze each year according to atopic status at age 7 years.
Table 2 Frequency $(\%)$ of symptoms in sowa and control groups

\begin{tabular}{llll}
\hline & $\begin{array}{l}\text { Soya } \\
\text { group } \\
n=215\end{array}$ & $\begin{array}{l}\text { Control } \\
\text { group } \\
n=231\end{array}$ & $\begin{array}{l}\text { Difference, } \\
\text { sola-control } \\
95^{\circ}{ }_{0}(C I\end{array}$ \\
\hline Wheeze at any time & 69 & 68 & $1-8$ to 10$)$ \\
Asthma parents' report & 21 & 22 & $-1-8$ to 7$)$ \\
Asthma diagnosis) & 28 & 35 & $-7-16$ to 2$)$ \\
Eczema diagnosis) & 37 & 36 & $0 \cdot 4-9$ to 9 \\
Allergic rhinitis diagnosis) & 28 & 25 & $3(-5$ to 12$)$ \\
\hline
\end{tabular}

CI = confidence interval.

Table 3 Frequency $(\%)$ of symptoms in children ever and never breast fed

\begin{tabular}{llll}
\hline & $\begin{array}{l}\text { Ever } \\
\text { breast fed } \\
n=179\end{array}$ & $\begin{array}{l}\text { Never } \\
\text { breast fed } \\
(n=274\end{array}$ & $\begin{array}{l}\text { Difference, } \\
\text { nezer-ezer } \\
95^{\circ}{ }^{\circ}(I)\end{array}$ \\
\hline Wheeze at any time & $59 \star \star \star$ & 74 & $15(61024)$ \\
Asthma (parents' report) & 23 & 20 & $-2(-10$ to 5 \\
Asthma (diagnosis) & 27 & 34 & $7(-2$ to 15 \\
Eczema diagnosis & 37 & 35 & $-1(-11$ to 8$)$ \\
Allergic rhinitis (diagnosis & 26 & 27 & $1-7$ to 9$)$ \\
\hline
\end{tabular}

$\mathrm{CI}=$ confidence interval.

$\star \star \star p<0.001$.

denotes those children who, in the paediatrician's opinion, had had asthma at any time. 'Eczema (diagnosis)' includes current eczema and a history of eczema within the past year, according to the paediatrician's opinion. 'Allergic rhinitis (diagnosis)' similarly relates to the previous 12 months. At the age of 7, a history of asthma and the doctor's diagnosis of it occurred more frequently in boys than in girls, and a wheeze was reported more frequently in the annual questionnaires among the boys than among the girls. Eczema was diagnosed more frequently among the girls at 7 years. There was a non-significant tendency for allergic rhinitis to occur more among the boys than among the girls.

Table 2 shows the same data according to the original randomisation groups. The numbers are slightly less than those in table 1 because a few children were excluded from the randomised trial but not from the observational data. ${ }^{1}$ No significant differences occurred between the two groups.

Figure 1 shows the percentage of children who were reported to have wheezed each year. The children are classified into those who were and were not atopic at the age of 7 , where atopy is defined as the occurrence of any positive skin test weal at least $3 \mathrm{~mm}$ greater in diameter than the control weal. The proportion of children who wheezed tended to decline among those who were non-atopic and to increase among those who were atopic.

In table 3 the children are classified into those who had ever been breast fed (for however short a time) and those who had not. A history of wheeze was significantly less common among children who had ever been breast fed. No significant differences were found in respect of asthma, eczema, or allergic rhinitis.

Figure 2 displays the odds ratios for risk of wheeze during successive years among children who were ever breast fed compared with those who were not. The vertical bars represent $95 \%$ confidence intervals, so that a bar that does not cross the horizontal line implies a risk signific- 


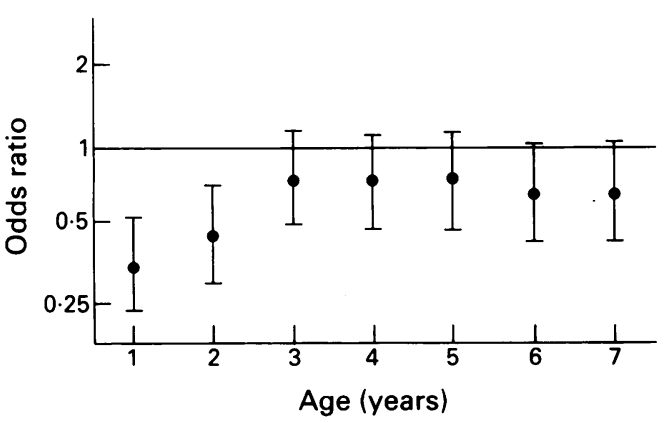

Figure 2 Annual risk of wheeze: ever v never breast fed (odds ratios with $95 \%$ confidence intervals).

antly different from unity at $\mathrm{p}<0 \cdot 05$. The risk of wheezing was significantly reduced by breast feeding for the first two years of life; thereafter the risk remained lower in the breast fed but never quite achieved statistical significance. The effect of breast feeding was then examined separately in the atopic and non-atopic children (defined as above). Figure 3 shows that after the second year of life the favourable implications of breast feeding persisted among those who were non-atopic but not among those who were atopic. Duration of breast feeding was significantly related to wheeze during the seventh year in those who were non-atopic, the odds ratio being 0.90 for each week of breast feeding ( $95 \%$ confidence interval 0.83 to 0.97 ): that is, for each additional week, the risk of wheezing was reduced by a factor of $0 \cdot 9$.

The social class of the children was determined in terms of the current occupation of the main wage earner at 7 years. Wheeze during the
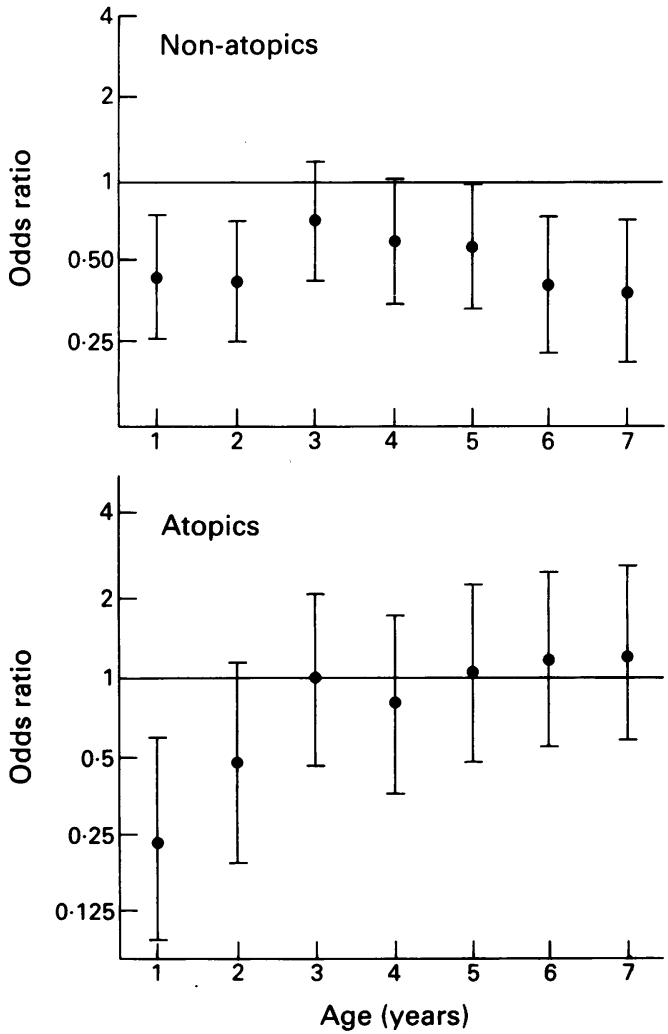

Figure 3 Annual risk of wheeze in 109 atopic and 327 nonatopic children: ever $\mathrm{v}$ never breast fed (odds ratios with $95 \%$ confidence intervals).
Table 4 Risk of wheeze during the seventh year in 274 nonatopic children, adjusting for possible confounders

\begin{tabular}{ll}
\hline Explanatory variable & Odds ratio $(95 \% C I)$ \\
\hline Breast fed: ever $v$ never & $0.52(0 \cdot 27$ to 0.98$)$ \\
Employed $v$ not employed & $0 \cdot 38(0 \cdot 21$ to $0 \cdot 70)$ \\
Sex: F $v M$ & $0.91(0.53$ to $1 \cdot 59)$ \\
Smoker in house $v$ no smoker & $1 \cdot 58(0 \cdot 87$ to $2 \cdot 86)$ \\
Overcrowding (person/room) & $1 \cdot 31(0.48$ to $3 \cdot 61)$ \\
\hline
\end{tabular}

$\mathrm{CI}=$ confidence interval.

seventh year was reported in $27 \%$ of those in social classes I-III non-manual, $24 \%$ in those in classes III manual-V, and $42 \%$ in those whose parents stated they were unemployed, the difference between employed and unemployed being highly significant $(p<0.01)$. This difference was found only among the non-atopic children, for whom the incidence of wheezing among the employed and unemployed groups was $17 \%$ and $40 \%$ respectively $(\mathrm{p}<0.001)$. As previously reported, ${ }^{2}$ there was a strong association at 1 year of age between wheezing and the presence of a smoker (particularly the mother) in the house, and this association persisted when several other factors were allowed for by means of logistic regression. At the age of 7 years the presence of a smoker in the house (as reported then) was significantly associated with wheeze in the past year among those who were non-atopic only, the incidence of wheezing being $15 \%$ where nobody smoked and $28 \%$ where someone smoked $(\mathrm{p}<0.01)$. Among the atopic children there were no associations between wheeze and smoking at any time (including smoking in pregnancy), and smoking was unrelated to asthma, eczema, and allergic rhinitis.

Table 4 examines the independent effects of each of five variables on wheeze among nonatopic children when the other four variables were allowed for, using logistic regression. Breast feeding and employment status retained their effects on risk of wheezing during the seventh year of life. This criterion was chosen as the other information was recorded at age 7 and might be expected to show the clearest associations with recent history. There was some association between smoking in the house and recent wheezing, but the relationship was not statistically significant after the other factors were allowed for.

Other data may be briefly summarised. Wheezing was not associated with cat ownership, mode of heating, the presence of damp patches or mould inside the house, the number of people living in the house, or the degree of overcrowding (number of people divided by number of rooms). When the initial exposure to mite antigen was classified as low, medium, and high the proportions of children with positive mite skin tests at age 7 were $20 \%, 20 \%$, and $22 \%$ respectively. Among children with low, medium, and high mite exposure at age 7 , skin tests were positive for mites in $19 \%, 19 \%$, and $23 \%$ respectively. The mite antigen concentrations in the first and seventh years did not differ significantly between the atopic wheezers and non-wheezers. Positive skin tests to cat antigen at age 7 were not related to the possession of a cat at age 1 nor at age 7. Mean PEFR (adjusted for 
height) was lower in the wheezers, both atopic and non-atopic, than in the non-wheezers $(220$, 222 , and $235 \mathrm{l} / \mathrm{min}$ respectively: $\mathrm{p}<0.001$ comparing each group of wheezers with nonwheezers). The PEFR after exercise as a percentage of the initial value was lower for the atopic wheezers than for the non-atopic wheezers and the non-wheezers $(91 \cdot 4 \%, 98 \cdot 2 \%$, and $98.8 \%$ respectively: $\mathrm{p}<0.001$ atopic wheezers $v$ nonwheezers).

\section{Discussion}

This study concerns children living in an area that has a high prevalence of chest disease. ${ }^{3}$ They were further selected so as to have an above average risk of allergy in that they all had a first degree relative with a history of atopic disease. This selective process is likely to facilitate the recognition of factors that predict respiratory symptoms, although it does not necessarily follow that they would operate in the same way in a different group of children. The follow up rate was high $(91 \%$ of the original cohort), so that there was little danger of bias arising from differential follow up. The annual questionnaires ensured that a transient period of wheezing was recorded while it was still remembered, and dated fairly accurately. Overall, $68 \%$ of the children wheezed at some time; by comparison, $63 \%$ of a similarly defined group of children in another area wheezed by the age of 11 years. ${ }^{8}$ The lower mean PEFR in wheezers compared with non-wheezers shows that a parental report of wheezing was accompanied by some objective evidence of impaired function. The excess frequency of wheezing and asthma among the boys, and of eczema among the girls, accords with findings from other surveys. ${ }^{-11}$

The withholding of cows' milk protein did not produce any decrease in the frequency of wheeze, asthma, eczema, or allergic rhinitis. Compliance was reasonably good, though not perfect: cows' milk protein was taken at least once in the first four weeks by $11 \%$ of babies in the intervention group and by $91 \%$ of the controls, and in the first three months by $26 \%$ and $96 \%$ respectively. ${ }^{1}$ Objective evidence of differential exposure to cows' milk protein was provided by milk specific serum IgG $_{4}$ antibodies, which were detected in $37 \%$ of the intervention group and $70 \%$ of the control group at 3 months. ${ }^{5}$ The difference between the groups in this regard should have been sufficient to reveal an important protective effect of cows' milk avoidance if it existed, although admittedly a minor effect might have been undetected. These results conflict with the findings of Johnstone and Dutton, who reported a reduction in the 10 year incidence of asthma and perennial allergic rhinitis in children given soya milk in infancy rather than a cows' milk preparation. ${ }^{4}$ There was, however, some possibility of bias in their results, in that the children were not assessed 'blind' with regard to their early feeding history. The present findings accord with those of other workers ${ }^{12-14}$ in that the substitution of soya milk for cows' milk did not prevent allergic disease. Either cows' milk protein is not particularly allergenic or soya milk has an equal effect.
Other studies have suggested that early exposure to mite antigen ${ }^{15}$ or cat dander ${ }^{16}$ predispose to asthma in later years. In the present study, no associations were found between early exposure to mite antigen or cats and the development of atopy, wheezing, or a positive skin test at the age of 7 years. The lack of association between wheezing and current cat ownership is perhaps not surprising as families containing an allergic child tend not to keep a cat. ${ }^{17}$ Both mite and cat antigen seem to be sufficiently widespread to sensitise susceptible children irrespective of the degree of mite infestation or whether a cat lives in the same house. ${ }^{18}$

Respiratory disease in childhood can be caused by infection or allergy. A prospective study of 67 babies born to atopic families found that the onset of wheeze after the age of 2 years but not before - was associated with persistent wheeze, atopy, and bronchial hyper-reactivity at the age of 11 years, ${ }^{8}$ suggesting that infection predominates in wheezing illness before the age of 2 years and allergy thereafter. Similar conclusions emerged in the present study, in that the annual incidence of wheezing tended to decline after the age of 2 years in those who were nonatopic and increase marginally in those who were atopic. The atopic wheezers tended to respond to exercise by a fall in PEFR greater than that of the non-atopic wheezers and the non-wheezers, implying that exercise induced asthma was largely confined to the atopic group of wheezers.

Employment status had a major effect on nonatopic wheeze; the important factor was whether the parents were employed or not, rather than their social class. The 'unemployed' group contained a high proportion of one parent families, and presumably the child's susceptibility to wheeze was a reflection of fundamental social factors. It is noteworthy that socioeconomic status is a consistent feature of chronic respiratory disease, which seems to have a predilection for the less privileged groups quite apart from their smoking habits. ${ }^{19}$

Passive smoking is a recognised cause of respiratory symptoms in early childhood. ${ }^{20}$ In this study it was a major independent risk factor for wheeze during the child's first year of life; by the age of 7 years the effect was no longer statistically significant when allowance was made for certain other variables, although it was still quite large. The relationship between wheeze and passive smoking was confined to the nonatopic children - that is, maternal and other passive smoking did not appear to increase the risk of atopy nor of symptoms in the atopics, as has been suggested..$^{21} 22$

During the first year of life, wheezing occurred twice as frequently in those who were never breast fed as in those who had received any breast milk, and this relationship could not be accounted for by other factors such as social class, maternal smoking, or overcrowding. ${ }^{2}$ The present results show that this effect relates to duration of breast feeding, persists to the age of 7 years, and is restricted to the non-atopics after the age of 2. The absence of any protection against atopic wheeze, eczema, or allergic rhinitis concurs with the results of some studies $^{2123-25}$ and conflicts with others. ${ }^{26} 27$ 
Perhaps the prevention of allergy requires exclusive breast feeding ${ }^{28}$ (which was rare in our populations), dietary restrictions during lactation, and mite eradication, ${ }^{29}$ and even so the onset of allergic disorders may be merely postponed.

Thus these findings imply a reduction in wheezing due to infection rather than in wheezing due to allergy. The question arises as to whether this relationship is causal or whether it is attributable to confounding variables. Obviously those mothers who choose to breast feed their babies differ from those who do not, and these differences may be reflected in the risk of infection. The analysis allowed for the confounding effects of employment status, smoking habit, and overcrowding, each of which might be associated with both feeding practice and risk of infection. It may be that other factors are involved, such as standards of hygiene, which are difficult to define but have a major effect on disease transmission. But the effect would have to be very large, and the association with breast feeding very close, in order to explain the observed relationship.

Is there any plausible mechanism by which breast feeding could confer protection against respiratory infections up to the age of 7 years, apparently with undiminished effect? A group of Indian breast fed babies had a lower incidence of respiratory and other infections than bottle fed babies matched for socioeconomic status, parental education and occupation, and family size. ${ }^{27}$ In two British case-control studies infants with respiratory syncytial virus infection were less likely to have been breast fed than unaffected infants. The effect was not confined to current breast feeding, and the differences persisted when allowance was made for social class ${ }^{30}$ or a variety of confounding factors including smoking. ${ }^{31}$ One of these studies showed that respiratory syncytial virus neutralising activity was detectable in every one of 21 samples of human colostrum, 18 of which also contained specific IgA and IgG. ${ }^{30} \mathrm{~A}$ study in Brazil suggested that breast feeding reduces infant mortality from respiratory infection. ${ }^{32}$ A randomised controlled trial of expressed breast milk in 261 low birthweight infants showed highly significant protection against a variety of infections. ${ }^{33}$ Several follow up studies have shown that infants admitted to hospital with respiratory syncytial virus bronchiolitis have an increased incidence of wheeze over the next few years, ${ }^{34} 35$ so protection against the initial infection could confer longer term benefits. It is therefore not wholly implausible to postulate that breast feeding in infancy protects children against respiratory infections for several years.

This work was conducted with the aid of a grant from the Welsh Scheme for the Development of Health and Social Research.

1 Miskelly FG, Burr ML, Vaughan-Williams E, Fehily AM Butland BK, Merrett TG. Infant feeding and allergy. Arch Dis Child 1988; 63: 388-93.

2 Burr ML, Miskelly FG, Butland BK, Merrett TG, VaughanWilliams $E$. Environmental factors and symptoms in infants at high risk of allergy. $\mathcal{F}$ Epidemiol Community Health 1989; 43: $125-32$.

3 Colley JRT, Reid DD. Urban and social origins of childhood bronchitis in England and Wales. BMF 1970; ii: 213-7.

4 Johnstone DE, Dutton AM. Dietary prophylaxis of allergic disease in children. N Engl F Med 1966; 274: 715-9.

5 Merrett TG, Burr ML, Butland BK, Merrett J, Miskelly FG, Vaughan-Williams E. Infant feeding and allergy: 12-month prospective study of 500 babies born into allergic families. prospective study of 500 babies born

6 Burr ML, St Leger AS, Bevan C, Merrett TG. A community survey of asthmatic characteristics. Thorax 1975; 30: 663-8.

7 Luczynska CM, Arruda K, Platts-Mills TAE, Miller J, Lopez $M$, Chapman MD. A two-site monoclonal antibody ELISA for the quantification of the major Dermatophagoides allergens, Der $\mathrm{p}$ I and Der f I. F Immunol Methods 1989; 118: 227-35.

8 Sporik R, Holgate ST, Cogswell JJ. Natural history of asthma in childhood - a birth cohort study. Arch Dis Child 1991; 66: 1050-3.

9 Gregg I. Epidemiological aspects. In: Clark TJH, Godfrey S, eds. Asthma. 2nd Ed. London: Chapman and Hall, 1983: 242-84.

10 Arbeiter HI. How prevalent is allergy among United States school children. A survey of findings in the Munster (Indiana) school system. Clin Pediatr (Phila) 1967; 6: 140-2.

$11 \mathrm{Kjellman}$ N-IM. Atopic disease in seven-year-old children. Incidence in relation to family history. Acta Paediatr Scand 1977; 66: 465-71.

12 Kjellman N-IM, Johansson SGO. Soy versus cow's milk in infants with a biparental history of atopic disease: developyears of age. Clinical Allergy 1979; 9: 347-58.

13 Gruskay FL. Comparison of breast, cow, and soy feedings in the prevention of onset of allergic disease. A 15-year
prospective study. Clin Pediatr (Phila) 1982; 21:486-91.

14 Moore WJ, Midwinter RE, Morris AF, Colley JRT, Soothill JF. Infant feeding and subsequent risk of atopic eczema. Arch Dis Child 1985; 60: 722-6.

15 Sporik R, Holgate ST, Platts-Mills TAE, Cogswell JJ. Exposure to house-dust mite allergen (Der $\mathrm{p} I$ ) and the development of asthma in childhood. A prospective study. N Engl F Med 1990; 323: 502-7.

16 Suoniemi I, Björkstén F, Haahtela T. Dependency of immediate hypersensitivity in the adolescent period on factors encountered in infancy. Allergy 1981; 36: 263-8.

17 Brunekreef B, Groot B, Hoek G. Pets, allergy and respiratory symptoms in children. Int $\mathcal{F}$ Epidemiol 1992; 21 : 338-42.

18 Warner JA. Environmental allergen exposure in homes and schools. Clin Exp Allergy 1992; 22: 1044-5.

19 Strachan DP. Causes and control of chronic respiratory disease - looking beyond the smokescreen. F Epidemiol Community Health 1992; 46: 177-9.

20 Chen $\mathrm{Y}, \mathrm{Li} \mathrm{W}, \mathrm{Yu} \mathrm{S}$. Influence of passive smoking on admissions for respiratory illness in early childhood. $B M \mathcal{F}$ 1986; 293: 303-6.

21 Cogswell JJ, Mitchell EB, Alexander J. Parental smoking, breast feeding, and respiratory infection in development of allergic diseases. Arch Dis Child 1987; 62: 338-44.

22 Magnusson CGM. Maternal smoking influences cord serum IgE and IgD levels and increases the risk for subsequent infant allergy. F Allergy Clin Immunol 1986; 78: 898-904.

23 Fergusson DM, Horwood LJ, Beautrais AL, Shannon FT, Taylor B. Eczema and infant diet. Clinical Allergy 1981; 11: 325-31.

24 Kramer MS, Moroz B. Do breast-feeding and delayed introduction of solid foods protect against subsequent atopic eczema? F Pediatr 1981; 98: 546-50.

25 Taylor B, Wadsworth J, Golding J, Butler N. Breast feeding, eczema, asthma, and hayfever. $\mathcal{F}$ Epidemiol Community Health 1983; 37: 95-9.

26 Grulee CG, Sanford HN. The influence of breast and artificial feeding on infantile eczema. F Pediatr 1936; 9: 223-5.

27 Chandra RK. Prospective studies of the effect of breast feeding on incidence of infection and allergy. Acta Paediatr Scand 1979; 68: 691-4.

28 Pratt HF. Breastfeeding and eczema. Early Hum Dev 1984; 9: 283-90.

29 Arshad SH, Matthews S, Gant C, Hide DW. Effect of allergen avoidance on development of allergic disorders in infancy. avoidance on developmen
Lancet 1992; 339: 1493-7.

30 Downham MAPS, Scott R, Sims DG, Webb JKG, Gardner PS. Breast-feeding protects against respiratory syncytial virus infections. $B M \mathcal{F}$ 1976; ii: $274-6$.

31 Pullan CR, Toms GL, Martin AJ, Gardner PS, Webb JKG, Appleton DR. Breast-feeding and respiratory virus infection. $B M \mathscr{F}$ 1980; 281: 1034-6.

32 Victora CG, Smith PG, Vaughan JP, et al. Evidence for protection by breast feeding against infant deaths from infectious diseases in Brazil. Lancet 1987; ii: 319-22.

33 Narayanan I, Prakash K, Prabhakar AK, Gujral VV. Planned prospective evaluation of the anti-infective property of varying quantities of expressed human milk. Acta Paediat Scand 1982; 71: 441-5.

34 Sims DG, Gardner PS, Weightman D, Turner MW, Soothill JF. Atopy does not predispose to RSV bronchiolitis or post b. Acplitic wheezing. BMF 1981;282: 2086-8.

35 Pullan CR, Hey EN. Wheezing, asthma, and pulmonary dysfunction 10 years after infection with respiratory syncytial virus in infancy. BMF 1982; 284: 1665-9. 